\title{
Assessment of Foetal DNA in Maternal Blood - A Useful Tool in the Hands of Prenatal Specialists
}

\author{
Bestimmung der fetalen DNA im mütterlichen Blut - \\ Sinnvoller Einsatz in der Hand des Pränatalmediziners
}

Authors

Affiliations
K. O. Kagan ${ }^{1}$, M. Hoopmann ${ }^{1}$, P. Kozlowski ${ }^{2}$

${ }^{1}$ Department of Obstetrics and Gynaecology, University of Tübingen

2 praenatal.de, Praenatal-Medizin und Genetik Düsseldorf

\author{
Key words \\ - foetal DNA \\ - ultrasound \\ - first trimester screening \\ - trisomy \\ Schlüsselwörter \\ - fetale DNA \\ - Ultraschall \\ - Ersttrimesterscreening \\ - Trisomie
}

\section{received 19.9.2012 \\ revised 19.10.2012 \\ accepted 21.10.2012}

Bibliography

DOI http://dx.doi.org/

10.1055/s-0032-1327960

Geburtsh Frauenheilk 2012; 72 :

998-1003 @ Georg Thieme

Verlag KG Stuttgart . New York . ISSN 0016-5751

\section{Correspondence}

Dr. Karl Oliver Kagan, MD, PhD

University of Tübingen

Department of Obstetrics

and Gynaecology

Calwer Straße 7

72076 Tübingen

KOKagan@gmx.de

\section{Abstract \\ $\nabla$}

Over the last few years, first trimester screening between $11+$ and $13+$ weeks of gestation has become one of the most important ultrasound examinations in pregnancy, as it allows physicians to predict several pregnancy complications including pre-eclampsia or pre-term birth. Screening for trisomies 21/18 and 13 using maternal and gestational age, foetal nuchal translucency, and maternal serum biochemistry was formerly the main reason for first trimester screening. However, today this is only one part of the overall examination. In the near future, the analysis of foetal DNA obtained from maternal blood will be used to supplement first trimester screening for aneuploidy or even replace current screening methods. In this review we show how prenatal medicine specialists can use foetal DNA analysis.

\section{Zusammenfassung \\ $\nabla$}

Das Ersttrimesterscreening in der $11+$ bis $13+$ SSW hat sich in den vergangenen Jahren zu einer der zentralen Ultraschalluntersuchungen in der Schwangerschaft entwickelt, welche die Prädiktion zahlreicher Probleme in der Schwangerschaft, wie Präeklampsie oder Frühgeburtlichkeit, erlaubt. Die eigentliche Risikoberechnung für Trisomie 21/18 und 13 , basierend auf dem mütterlichen Altersrisiko, der fetalen Nackentransparenz und der maternalen Serumbiochemie, stellt dabei nur einen der Schwerpunkte dar, der zukünftig durch die fetale DNA-Analyse aus mütterlichem Blut ergänzt bzw. abgelöst wird. In dieser Übersichtsarbeit wird der Einsatz der fetalen DNAAnalyse in der Hand des Pränatalmediziners beleuchtet.

\section{Introduction}

\section{$\nabla$}

In the last few years, first trimester screening (FTS) in $11+$ to $13+$ weeks of gestation (12th to 14 th weeks of gestation) has become one of the most important ultrasound examinations in pregnancy, as it allows physicians to predict several pregnancy complications [1].

While, initially, the main focus was to determine the personal risk for trisomies 21,18 and 13 , today around half of all severe foetal defects can be recognised at the time of FTS. In addition, the risks for pre-eclampsia, growth retardation and pre-term birth can be determined. Various interventions and therapies are now available to treat many of these problems in patients considered at particular risk $[2,38]$.

The use of foetal DNA obtained from maternal blood and massively parallel sequencing has made it possible to detect foetal trisomy 21 with a high degree of probability already in the first tri- mester of pregnancy [3]. At a casual glance it would appear that use of foetal DNA to assess the risk for trisomy 21 now competes with FTS. But on more careful examination of these tests it becomes clear that assessment of foetal DNA has the potential to become an important tool for prenatal medicine specialists in future. This review offers an assessment of foetal DNA analysis in the context of current prenatal medical questions and demonstrates the practical uses of this approach.

\section{Assessment of Free Foetal DNA from Maternal Blood \\ $\nabla$}

The detection of foetal DNA in maternal blood or, to be more precise, in cell-free maternal plasma goes back to a study by Lo et al. published in 1997 [4]. Pregnancy-specific cell-free DNA in maternal blood or plasma constitutes around $10 \%$ of all cell-free DNA, is largely fragmented and is not 
detectable a few hours after birth. In actual fact, the pregnancyspecific share is of placental and not of foetal origin, although "foetal DNA" is the term commonly used to refer to it.

Foetal DNA was initially used to determine an infant's rhesus status from maternal blood in cases of potential rhesus incompatibility. This approach is now well established and has replaced the former use of amniocentesis to determine the infant's rhesus status.

Using foetal DNA in screening for aneuploidy proved to be more difficult, as the maternal share of cell-free DNA which can be attributed to chromosome 21 predominates [5]. After initial attempts to isolate foetal DNA, scientists moved on to measure all of the cell-free DNA, i.e., both maternal and foetal DNA. Although it is difficult to distinguish between foetal euploidy and aneuploidy due to the predominance of maternal DNA, the new technology of next generation sequencing has made it possible to establish this approach. After extracting all of the cell-free DNA from maternal blood, this is then amplified using massively parallel sequencing and quantitatively attributed to the corresponding chromosomes using the human reference genome.

The precondition for this is, however, that at least $4 \%$ of the cellfree DNA is of pregnancy-specific origin. If the percentage of pregnancy-specific cell-free DNA falls below this minimum level - which becomes more likely as maternal weight increases - it is not possible to make any statement about the foetal chromosomal status [6].

To detect an abnormal karyotype, only sequencing fragments which can be unambiguously assigned to a specific position on a chromosome in the genome are used for quantification. In cases with a euploid karyotype, around $1.25 \%$ of the DNA material are from chromosome 21 depending on the chosen sequencing technology, while if trisomy 21 is present, this figure rises to approximately $1.32 \%$. This difference is expressed as a z-score [7]. The cut-off point is set at a z-score of 3 which corresponds to three times the standard deviation for a euploid pregnancy.

Assessment of foetal DNA results in the detection of at least 95\% of all foetuses with trisomy 21 , with a maximum false positive rate of $0.5 \%$ (personal communication of Dr. Wera Hofmann, LifeCodexx AG, unpublished statement). In a first meta-analysis by Verweij et al., 556 euploid and 125 trisomy 21 pregnancies were investigated. The detection and false positive rates were $100 \%$ and $0.7 \%$, respectively. However, it should be noted that these data were based on only 2 studies. A further 7 studies were excluded for reasons of quality [8]. \ Table 1 offers an overview of recent studies.
To date, all reference data were obtained only from high-risk collectives and included only a limited number of pregnancies with trisomy 21, with euploid karyotypes being under-represented [3]. A screening study with a similar number of cases as that used to prove the screening performance of FTS for trisomy 21 is still lacking. Nevertheless, the expectation is that the screening performance of foetal DNA in a representative group will also be very good. In a first small screening study of 2038 euploid and 8 trisomy 21 pregnancies, the screening performance of foetal DNA was compared with that of FTS for trisomy. The detection and false positive rates for foetal DNA were $100 \%$ and $0.1 \%$, respectively, compared to $100 \%$ and $4.5 \%$ with FTS for trisomy [9].

Currently, the disadvantages of the test are its high cost (1250€ in Germany), the lengthy processing time (at least 2 weeks), and the fact that the test is limited to trisomy 21. Particularly in younger pregnant women, trisomy 21 is only present in around half of all cases with aneuploidy [10]. In the near future, tests for trisomies 18 and 13 are also expected to be available in the Germanspeaking countries; however, based on recent studies, the sensitivity of these tests is lower. Other numerical and structural chromosomal abnormalities cannot be detected. Moreover, problems arising from placental mosaicism also remain unresolved. As the foetal DNA found in maternal blood is mainly of placental origin and not of direct foetal origin, the test will always flag up placental mosaicism as an abnormality and will not be able to distinguish further. In any case, an invasive procedure will still be necessary to confirm an abnormal test result obtained by the assessment of foetal DNA in maternal blood.

\section{Assessment of Free Foetal DNA and Other Risk Stratifications Used in First Trimester Screening \\ $\nabla$}

With the establishment of FTS for trisomy, aneuploidy risk assessment in the first trimester has proven to be extremely valuable, particularly in view of patients' wish to undergo screening as early as possible. Thus, foetal DNA assessment will be primarily carried out in the first trimester of pregnancy.

It is safe to assume that, in the longer term, screening for aneuploidy will be managed better using foetal DNA than by using FTS for trisomy based on maternal and gestational age, foetal nuchal translucency, free beta-hCG and PAPP-A. This is predominantly due to the higher detection rates achieved by foetal DNA. In addition, the measurement of foetal nuchal translucency thickness is associated with a high inter-investigator variability. De-

Table 1 Overview of recent studies on foetal DNA analysis in maternal blood using "massively parallel sequencing” to detect trisomy 21.

\begin{tabular}{|c|c|c|c|c|}
\hline Study & Euploid (n) & Trisomy 21 (n) & Detection rate (\%) & False positive rate (\%) \\
\hline Fan et al. 2008 [28] & 18 & 9 & 100 & 0 \\
\hline Chiu et al. 2008 [6] & 14 & 14 & 100 & 0 \\
\hline Sehnert et al. 2011 [29] & 47 & 13 & 100 & 0 \\
\hline Chiu et al. $2011[30]^{1}$ & 146 & 86 & 100 & $2.1(1)$ \\
\hline Ehrich et al. 2011 [31] & 449 & 39 & 100 & 0.3 \\
\hline Palomaki et al. 2011 [32] & 1484 & 212 & 98.6 & 0.2 \\
\hline Sparks et al. 2012 [33] & 298 & 39 & 100 & 0 \\
\hline Stumm et al. 2012 [3] & 42 & 8 & 100 & 0 \\
\hline Bianchi et al. 2012 [34] & 532 & 89 & 100 & 0 \\
\hline Sparks et al. 2012 [35] & 167 & 35 & 100 & 0 \\
\hline Nicolaides et al. 2012 [9] & 2038 & 8 & 100 & 0.1 \\
\hline
\end{tabular}

1 2-plex protocol 
spite all attempts at standardisation and quality control, the measurement process remains error-prone $[11,12]$. Thus, an uncomplicated blood test would be easier to carry out, while the initial counselling offered prior to any tests in accordance with the German Genetic Diagnostics Act would not differ from the counselling given prior to FTS for trisomy.

Use of foetal DNA in a general population has not yet been sufficiently investigated. Most studies were limited to collectives known to be at increased risk. A larger screening study will be necessary before this test can be used more generally in low-risk collectives.

Measurement of nuchal translucency and careful assessment of foetal anatomy during the first trimester will continue to play an important role in pregnancy care, even after switching to foetal DNA, as numerous structural abnormalities and genetic syndromes are first recognised based on increased nuchal translucency or atypical sono-anatomy. Furthermore, as described above, the analysis of foetal DNA obtained from maternal blood is not always successful $[6,13,14]$. In view of the low detection rates for certain abnormalities - particularly for cardiac defects in the 2nd trimester, the use of surrogate markers for abnormalities detectable in the 1st trimester should not become less important [15]. A study which included approximately 40000 normal pregnancies and 85 foetuses with serious cardiac defects showed that combining the assessment of nuchal translucency with that of blood flow in the ductus venosus and through the tricuspid valve in the $12+$ week of gestation resulted in the detection of around $60 \%$ of all cardiac defects [16].

It has also been shown that the risk for numerous pregnancy complications can be assessed around 12+ weeks of gestation. Screening for pre-eclampsia is of particular importance, as its prevalence of between 1 and $2 \%$ justifies screening, and as the individual risk for pre-eclampsia can be reduced through the administration of aspirin to patients with an increased risk $[2,17]$. The screening study of Akolekar et al., the most comprehensive study to date, investigated around 33000 normal pregnancies and 752 pregnancies with subsequent pre-eclampsia in $11+$ to $13+$ weeks of gestation $[17,39]$. They found that a screening policy that was based on the combination of previous maternal history, maternal blood pressure, resistance in the uterine arteries, and the serum markers PAPP-A and PIGF provided detection rates of more than $85 \%$ of those pregnancies that resulted in pre-eclampsia prior to 34 weeks of gestation, with a false positive rate of $10 \%$. Today, the individual risk for developing pre-eclampsia can be calculated, just as the risk for trisomy 21 can be calculated.
In a meta-analysis by Bujold et al., they showed that daily administration of aspirin 100 in patients at increased risk could halve the individual risk for future pre-eclampsia, provided that regular medication was started prior to $16+$ weeks of gestation [2].

A number of other screening tests for late complications in pregnancy, such as cervical insufficiency, intrauterine foetal death, and SGA growth or growth retardation, are available in $11+$ to $13+$ weeks of gestation $[1,18]$. In some cases, these risk models are already being used in clinical practice, and in our experience patients are increasingly demanding their use. Risk assessment for aneuploidy represents an important but by no means the only approach in first trimester screening. This must always be taken into consideration when offering first-time counselling.

\section{First Trimester Screening for Trisomy with Free Foetal DNA}

$\nabla$

Currently, many physicians consider the assessment of foetal DNA in maternal blood to be an alternative to invasive diagnostic tests. But it must be remembered that invasive diagnostic tests are currently the gold standard, with a detection rate of practically $100 \%$ for numerical and structural chromosomal abnormalities recognisable with light microscopy. Any reduction of such detection rates would be unacceptable. However, as every invasive diagnostic test is associated with a risk of miscarriage which is about $0.5 \%$ higher than the natural miscarriage rate, the assessment of foetal DNA from a maternal blood sample would be preferable as it is not associated with an additional risk of miscarriage $[19,20]$.

It would be easier if the assessment of foetal DNA was considered a screening test for trisomy 21 . The detection and false positive rates for trisomy 21 of the PraenaTest offered by LifeCodexx are at least $95 \%$ and $0.5 \%$, resulting in a positive and a negative likelihood ratio of 190 and 0.05 , respectively. The advantage of using foetal DNA assessment becomes obvious when these figures are compared with the positive and negative likelihood ratios of 18 and 0.11 based on FTS for trisomy 21 , with detection and false positive rates of $90 \%$ and $5 \%$, respectively [21]. Even when additional ultrasound markers such as nasal bone length, tricuspid valve and ductus venosus flow are used, the figures are still $95 \%$ and $2.5 \%$ and thus lower than those for foetal DNA in maternal blood [22-24]. Table 2 offers an overview of the test quality of prenatal screening tests for trisomy 21.

Table 2 Overview of prenatal screening tests for trisomy 21.

\section{Test method used}

Analysis of foetal DNA obtained from maternal blood (PraenaTest ${ }^{\circledR}$, LifeCodexx AG)*

Combined first trimester screening between $11+$ and $13+$ weeks of gestation [21] (age, foetal NT, free beta-hCC and PAPP-A)

Combined first trimester screening and additional ultrasound markers [22-24] (nasal bone, tricuspid valve or ductus venosus flow)

Two-stage combined first trimester screening [36] (foetal NT in the 12+ week of gestation and serum biochemistry

in the $9+$ week of gestation)

Triple test in the 2nd trimester [37] (AFP, beta-hCG, estriol)

Quadruple test in the 2nd trimester [37] (AFP, beta-hCG, estriol und inhibin-A)

Integrated screening [37] (foetal NT and PAPP-A in the 12+ week of gestation and quadruple test in the 2nd trimester)

Sonographic soft marker screening in the 2nd trimester [27]

\begin{tabular}{|l|l|}
\hline $\begin{array}{l}\text { Detection rate } \\
\text { at least } 95 \%\end{array}$ & $\begin{array}{c}\text { False positive rate } \\
0.5 \%\end{array}$ \\
\hline about $90 \%$ & $5 \%$ \\
\hline about $95 \%$ & $2.5 \%$ \\
\hline about $90 \%$ & $3 \%$ \\
\hline about $60 \%$ & $5 \%$ \\
\hline about $70 \%$ & $5 \%$ \\
\hline about $85 \%$ & $5 \%$ \\
\hline about $75 \%$ & $13 \%$ \\
\hline
\end{tabular}

* currently only done in collectives at increased risk 


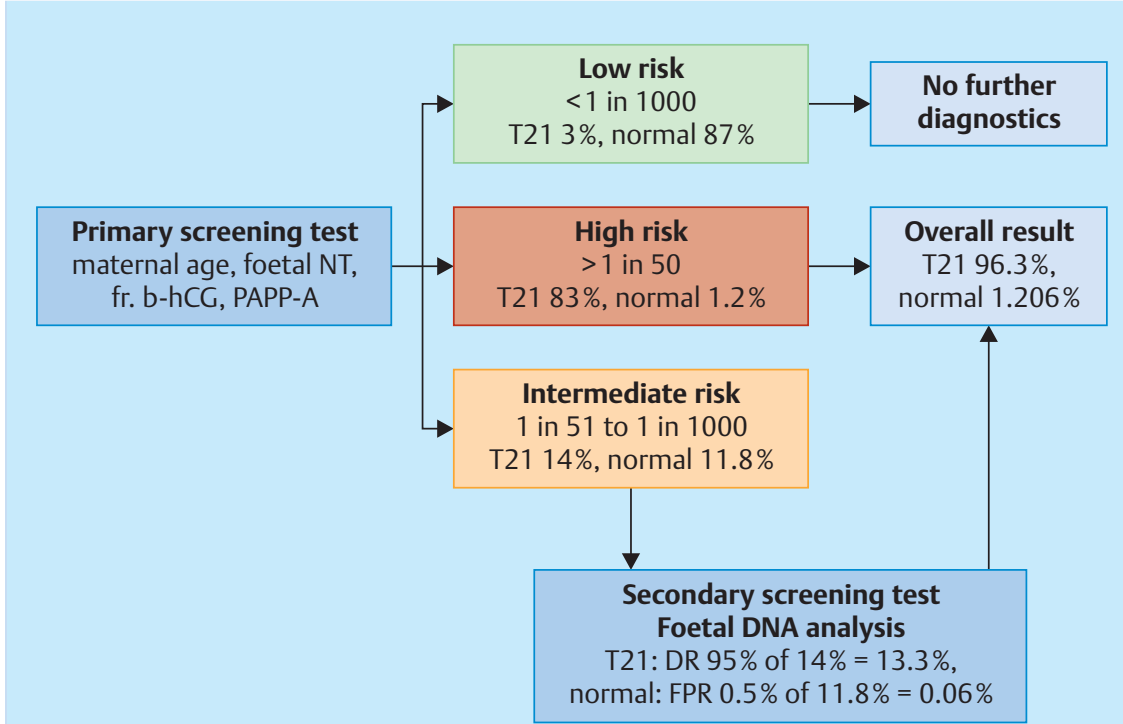

Fig. 1 Potential 2-stage model combining first trimester screening as the primary test and analysis of foetal DNA as the secondary test. Classic combined screening is done first as the primary screening test. The results are then used to classify patients into low, high and intermediate risk. The percentage of foetuses with trisomy 21 (T21) and of euploid foetuses in the corresponding total collective is shown for each risk class. No further testing is done in the low-risk group. They are considered screen-negative. The high-risk group is classified as screen-positive. In the intermediate risk group, foetal DNA analysis is done as the secondary screening test. The detection rate (DR) is $95 \%$ and it has a false positive rate (FPR) of $0.5 \%$. Patients who then have suspicious results are added to the screen-positive group, those with unremarkable results to the screen-negative group. This allows $96.3 \%$ of trisomy 21 foetuses and $1.206 \%$ of euploid foetuses to be classified as screen-positive.

As the analysis of foetal DNA is expressed as z-scores, it is worth considering whether it would be possible to compute a continuous likelihood ratio from the z-scores, which could be multiplied with the maternal and gestational age-related risk. Using this patient-specific risk, the patient could decide for herself, as with FTS for trisomy, whether invasive testing would be justified after having weighed the different risks. Prior to the clinical introduction of this approach, validation in the form of a prospective study done in a general population would, of course, be necessary.

\section{Free Foetal DNA as a Secondary Test after Primary FTS for Trisomy}

Until free foetal DNA assessment to ascertain the individual trisomy risk has become a standard procedure and the current problems of high costs and limited availability have been overcome, foetal DNA assessment will have to be integrated in a higher-level screening concept. The obvious thing would be to include it in a 2-stage model of FTS for trisomy. The primary test would consist of FTS risk assessment, and the analysis of foetal DNA would serve as secondary test in a subgroup of patients. The advantage of this two-stage model is the widespread availability of FTS for trisomy, the lower costs, and the opportunity to use FTS as a triage test to detect markers for chromosomal abnormalities other than trisomy 21.

The first step would consist of computing the patient-specific risk, based on maternal and gestational age-related risk, foetal nuchal translucency, and the serum markers free beta-hCG and PAPP-A. Patients would subsequently be categorised as high risk, intermediate risk or low risk. The Foetal Medicine Foundation London recommends using cut-off risks of 1 in 50 and 1 in 1000 [22-24]. Around $1 \%$ of euploid foetuses are found in the high-risk group and $12 \%$ and $87 \%$ in the intermediate-risk and low-risk collectives. $83 \%, 14 \%$ and 3\%, respectively, of trisomy 21 foetuses are found in the high-risk, intermediate-risk and low-risk groups [25].

Even if up to now, studies have not focussed much on other chromosomal disorders, it can be safely assumed that, based on in- creased nuchal translucency and low PAPP-A values, most chromosomal disorders will also be found in the high-risk group. The risk distribution for trisomies 18 and 13 shows an even more pronounced bias towards the high-risk group [26].

If FTS for trisomy flags up a high-risk result, then assessment of foetal DNA to exclude aneuploidy is not useful, as this high-risk result indicates an increased risk for a number of chromosomal disorders - not merely for trisomy 21 . Thus, a test which only focussed on trisomy 21 would lull the patient into a false sense of security. If the result indicates a low risk, then additional foetal DNA assessment is also not useful. The median risk for trisomy 21 in this group is around 1 in 14500 (based on an age-independent prevalence of trisomy 21 of 1 in 500 and a prevalence of $3 \%$ of trisomy 21 pregnancies and of $87 \%$ of euploid pregnancies in the low risk group). The risk for other chromosomal disorders is therefore generally higher than the risk for trisomy 21 .

However, the use of foetal DNA is conceivable in the intermediate risk group. Previously, the new ultrasound markers "foetal nasal bone", "tricuspid valve and ductus venosus flow" were used in this risk group, with detection and false positive rates of around 50-65\% and 1-3\%; if foetal DNA assessment in maternal blood were added, this could result in a better assessment of risk [2224].

As shown in - Fig. 1, this 2-stage model reduces the false positive rate to approximately $1-1.5 \%$ and increases the detection rate to over $95 \%$. At the same time, foetal DNA assessment will only be necessary in around $15 \%$ of cases. However, this approach also needs to be validated in clinical studies.

Foetal DNA analysis for trisomy 21 is not useful in cases with malformations such as radial aplasia due to the multiple associated chromosomal disorders.

The use of foetal DNA assessment described above shows that the prior use of ultrasound screening is crucial. Prior risk assessments must be appropriate, and even atypical chromosomal abnormalities need to be recognised and taken into account. Thus, before assessing foetal DNA in maternal blood, it is first necessary to carry out detailed FTS (by an experienced investigator). It is very important to remember that only about half of all chromosomal disorders can be ascribed to trisomy 21 , that foetal 
chromosomal disorders only account for around $10 \%$ of all malformations, and that malformations are only responsible for around one third of perinatal mortalities. Investigations must therefore comprehensively focus on the most common pregnancy complications, as the risk of such complications can generally already be assessed with FTS. Limiting investigations exclusively to trisomy 21 would underutilise the opportunities available today and would not sufficiently weigh up the pregnancyassociated risks.

\section{Use of Foetal DNA Assessment in the 2nd Trimester} $\nabla$

Foetal DNA assessment could also be used as an alternative to amniocentesis for advanced maternal age in the 17th week of gestation. After informing patients about the test quality, use of this test in the group of patients with advanced maternal age is quite conceivable. Foetal DNA assessment would be an excellent screening test in this collective and could increase and reduce the patient-specific risk by a factor of 190 and 0.05 , respectively. In practical terms, this would mean that a 40 -year-old patient with an age risk of around 1 in 100 would have a risk of 1 in 2 after the test (truncated) or 1 in 2000. Such a clear reduction does not in most cases justify the use of invasive diagnostics. But as with FTS, a previous detailed ultrasound investigation which would assess the risk for other chromosomal disorders is obligatory.

It should be noted that amniocentesis based on the indication 'maternal age' is increasingly being replaced by FTS and thus only plays a subordinate role.

The use of foetal DNA assessment after multiple marker screening (done as part of the detailed anomaly scan) in the 21 st week of gestation is also conceivable. If a constellation of markers is found which appear to be typical for trisomy 21, use of foetal DNA assessment with the likelihood ratios referred to above could provide results which would clearly show whether the risk was reduced and so prevent the patient from undergoing invasive tests [27]. But here again, it must be emphasised that risk assessment for trisomy 21 based on multiple marker screening in the 20+ week of gestation has become much less important since FTS has come into more general use.

\section{General Outlook \\ $\nabla$}

We can safely assume that first trimester screening will play an increasingly important role in the future in the assessment of pregnancies. But the focus will no longer be on screening for trisomy 21 but on early detailed ultrasound scans which will be combined with a number of different risk algorithms to assess pregnancy-specific complications such as pre-eclampsia. If the current problems of limited availability and high cost are resolved and it becomes possible to carry out the test prior to 10+ weeks of gestation, as is currently planned, by the time of first trimester screening the risk assessment for trisomies 21/18/13 will already have been concluded based on an analysis of foetal DNA. If first trimester screening or assessment of free foetal DNA indicates that another chromosomal abnormality is present or if the assessment of free foetal DNA indicates that trisomy 21/18/13 is present, an invasive procedure will still be necessary, for the time being, to confirm the abnormal test result. If a risk assessment is not possible because the foetal DNA concentration is too low, it will be necessary to switch to classical FTS risk assessment for trisomy. Should, despite everything, an invasive test still be necessary, then the focus will be on new and more detailed investigative tests such as array CGH (comparative genomic hybridization).

In the more distant future, an analysis of the complete infantile genome in the $1 \mathrm{st}$ trimester will be technically possible. Whether the latter will actually find its way into clinical practice will depend both on the costs involved and on the ethical debates which such options will raise.

\section{Conclusion}

\section{$\nabla$}

In conclusion, the assessment of foetal DNA from maternal blood offers a new opportunity to simplify the risk assessment for trisomy 21 in early pregnancy in a subgroup of patients. If the detection rates should be confirmed in screening and the costs continue to drop, then in the coming years FTS for trisomy will be complemented or even replaced by foetal DNA assessment. To ensure optimal levels of patient care, it will be important to continue to carry out FTS as it offers numerous opportunities to influence the course of the pregnancy. Any development in which FTS is only used to date the pregnancy, in which an assistant takes a blood sample to determine foetal DNA, and all other potential problems are only tackled in the 20 + weeks of gestation would represent a setback of more than 20 years.

\section{Acknowledgement}

We would like to thank Dr. Wera Hofmann (LifeCodexx AG, Konstanz) for her critical review of the manuscript.

\section{Conflict of Interest}

$\nabla$

None.

\section{Literatur}

1 Nicolaides KH. Turning the pyramid of prenatal care. Fetal Diagn Ther 2011; 29: 183-196

2 Bujold E, Roberge S, Lacasse Y et al. Prevention of preeclampsia and intrauterine growth restriction with aspirin started in early pregnancy: a meta-analysis. Obstet Gynecol 2010; 116 (2 Pt 1): 402-414

3 Stumm M, Entezami M, Trunk $N$ et al. Noninvasive prenatal detection of chromosomal aneuploidies using different next generation sequencing strategies and algorithms. Prenat Diagn 2012; 32: 569-577

4 Lo YM, Corbetta N, Chamberlain PF et al. Presence of fetal DNA in maternal plasma and serum. Lancet 1997; 350: 485-487

5 Chiu RWK, Lo YMD. Noninvasive prenatal diagnosis empowered by high-throughput sequencing. Prenat Diagn 2012; 32: 401-406

6 Ashoor G, Poon L, Syngelaki A et al. Fetal fraction in maternal plasma cell-free DNA at 11-13 weeks' gestation: effect of maternal and fetal factors. Fetal Diagn Ther 2012; 31: 237-243

7 Chiu RWK, Chan KCA, Gao Yet al. Noninvasive prenatal diagnosis of fetal chromosomal aneuploidy by massively parallel genomic sequencing of DNA in maternal plasma. Proc Natl Acad Sci U S A 2008; 105: 2045820463

8 Verweij EJ, van den Oever JME, de Boer MA et al. Diagnostic accuracy of noninvasive detection of fetal trisomy 21 in maternal blood: a systematic review. Fetal Diagn Ther 2012; 31: 81-86

9 Nicolaides KH, Syngelaki A, Ashoor G et al. Noninvasive prenatal testing for fetal trisomies in a routinely screened first-trimester population. Am J Obstet Gynecol 2012; 207: 374.e1-374.e6 
10 Grati FR, Barlocco A, Grimi B et al. Chromosome abnormalities investigated by non-invasive prenatal testing account for approximately $50 \%$ of fetal unbalances associated with relevant clinical phenotypes. Am J Med Genet 2010; 152: 1434-1442

11 Wright D, Kagan KO, Molina FS et al. A mixture model of nuchal translucency thickness in screening for chromosomal defects. Ultrasound Obstet Gynecol 2008; 31: 376-383

12 Abele $H$, Wagner $N$, Hoopmann $M$ et al. Effect of deviation from the midsagittal plane on the measurement of fetal nuchal translucency. Ultrasound Obstet Gynecol 2010; 35: 525-529

13 Syngelaki A, Chelemen T, Dagklis T et al. Challenges in the diagnosis of fetal non-chromosomal abnormalities at 11-13 weeks. Prenat Diagn 2011; 31: 90-102

14 Timmerman E, Pajkrt E, Maas SM et al. Enlarged nuchal translucency in chromosomally normal fetuses: strong association with orofacial clefts. Ultrasound Obstet Gynecol 2010; 36: 427-432

15 Kagan KO, Hoopmann M, Abele $\mathrm{H}$ et al. Zukünftige Entwicklung der $\mathrm{Ge}$ burtsmedizin. Gynäkologe 2012; DOI 10.1007/s00129-012-2964-2

16 Pereira S, Ganapathy R, Syngelaki A et al. Contribution of fetal tricuspid regurgitation in first-trimester screening for major cardiac defects. Obstet Gynecol 2011; 117: 1384-1391

17 Akolekar R, Syngelaki A, Sarquis R et al. Prediction of early, intermediate and late pre-eclampsia from maternal factors, biophysical and biochemical markers at 11-13 weeks. Prenat Diagn 2011; 31: 66-74

18 Greco E, Gupta R, Syngelaki A et al. First-trimester screening for spontaneous preterm delivery with maternal characteristics and cervical length. Fetal Diagn Ther 2012; 31: 154-161

19 Kozlowski P, Knippel A, Stressig R. Individual risk of fetal loss following routine second trimester amniocentesis: a controlled study of 20,460 cases. Ultraschall Med 2008; 29: 165-172

20 Tabor A, Alfirevic Z. Update on procedure-related risks for prenatal diagnosis techniques. Fetal Diagn Ther 2010; 27: 1-7

21 Kagan KO, Wright D, Baker A et al. Screening for trisomy 21 by maternal age, fetal nuchal translucency thickness, free beta-human chorionic gonadotropin and pregnancy-associated plasma protein-A. Ultrasound Obstet Gynecol 2008; 31: 618-624

22 Kagan KO, Valencia C, Livanos $P$ et al. Tricuspid regurgitation in screening for trisomies 21,18 and 13 and Turner syndrome at $11+0$ to $13+6$ weeks of gestation. Ultrasound Obstet Gynecol 2009; 33: 18-22

23 Maiz N, Valencia C, Kagan KO et al. Ductus venosus Doppler in screening for trisomies 21, 18 and 13 and Turner syndrome at 11-13 weeks of gestation. Ultrasound Obstet Gynecol 2009; 33: 512-517

24 Kagan KO, Cicero S, Staboulidou I et al. Fetal nasal bone in screening for trisomies 21, 18 and 13 and Turner syndrome at 11-13 weeks of gestation. Ultrasound Obstet Gynecol 2009; 33: 259-264
25 Kagan KO, Etchegaray A, Zhou Y et al. Prospective validation of first-trimester combined screening for trisomy 21. Ultrasound Obstet Gynecol 2009; 34: 14-18

26 Kagan KO, Wright D, Valencia C et al. Screening for trisomies 21, 18 and 13 by maternal age, fetal nuchal translucency, fetal heart rate, free-hCG and pregnancy-associated plasma protein-A. Hum Reprod 2008; 23: 1968-1975

27 Nicolaides $\mathrm{KH}$. Screening for chromosomal defects. Ultrasound Obstet Gynecol 2003; 21: 313-321

28 Fan HC, Blumenfeld YJ, Chitkara $U$ et al. Noninvasive diagnosis of fetal aneuploidy by shotgun sequencing DNA from maternal blood. Proc Natl Acad Sci U S A 2008; 105: 16266-16271

29 Sehnert AJ, Rhees B, Comstock D et al. Optimal detection of fetal chromosomal abnormalities by massively parallel DNA sequencing of cellfree fetal DNA from maternal blood. Clin Chem 2011; 57: 1042-1049

30 Chiu RWK, Akolekar R, Zheng YWL et al. Non-invasive prenatal assessment of trisomy 21 by multiplexed maternal plasma DNA sequencing: large scale validity study. BMJ 2011; 342: c7401

31 Ehrich M, Deciu C, Zwiefelhofer $T$ et al. Noninvasive detection of fetal trisomy 21 by sequencing of DNA in maternal blood: a study in a clinical setting. Am J Obstet Gynecol 2011; 204: 205.e1-205.e11

32 Palomaki GE, Kloza EM, Lambert-Messerlian GM et al. DNA sequencing of maternal plasma to detect Down syndrome: an international clinical validation study. Genet Med 2011; 13: 913-920

33 Sparks AB, Wang ET, Struble CA et al. Selective analysis of cell-free DNA in maternal blood for evaluation of fetal trisomy. Prenat Diagn 2012; 32: 3-9

34 Bianchi DW, Platt LD, Goldberg JD et al. Genome-wide fetal aneuploidy detection by maternal plasma DNA sequencing. Obstet Gynecol 2012; 119: 890-901

35 Sparks AB, Struble CA, Wang ET et al. Noninvasive prenatal detection and selective analysis of cell-free DNA obtained from maternal blood: evaluation for trisomy 21 and trisomy 18. Am J Obstet Gynecol 2012; 206: 319.e1-319.e9

36 Wright D, Spencer K, Kagan KK et al. First-trimester combined screening for trisomy 21 at 7-14 weeks' gestation. Ultrasound Obstet Gynecol 2010; 36: 404-411

37 Cuckle HH, Benn PP, Wright DD. Down syndrome screening in the first and/or second trimester: model predicted performance using metaanalysis parameters. Semin Perinatol 2005; 29: 252-257

38 Hoopmann M, Abele H, Dufke A et al. Pränatale Diagnostik des SmithLemli-Opitz-Syndroms. Geburtsh Frauenheilkunde 2011; 71: 128-131

39 Osmanağaoğlu MA, Caner Karahan S, Aran T et al. Predictive value of plasma total carnitine, arginine, asymmetric dimethylarginine and ischemia-modified albumin levels and their combined use in the early detection of preeclampsia. Geburtsh Frauenheilk 2011; 71: 773-778

Deutschsprachige Zusatzinformationen online abrufbar unter: www.thieme-connect.de/ejournals/toc/gebfra. 